\title{
Unrecognised language teaching: Teaching Australian Curriculum content in remote Aboriginal community schools
}

\section{Susan Poetsch \\ School of Education and Social Work, The University of Sydney, Sydney, Australia.}

Abstract: The case study in this article offers a descriptive account of challenges involved in teaching Australian Curriculum content in the common teaching context in remote communities where an Indigenous language is spoken as the everyday form of communication and students learn English in what is essentially a foreign language setting. An on-theground description of the work of a Primary school teaching team serves to illustrate the language teaching aspect of delivering Australian Curriculum content in areas such as History, Geography and Science. This aspect of the teaching team's work is underestimated in the curriculum itself and in the guidance provided to teachers, yet is essential for student learning in this context. While the team draws on students' L1 and early L2 English proficiency abilities to teach curriculum content, this work is not expedited from outside their classroom. An analysis of current curriculum offerings and the teaching team's approaches finds that they receive little direction for the extensive language planning required. The findings suggest an urgent need for tailor-made curriculum and teacher guidance which better recognise this dual language context. This article canvases different curriculum settings that would alleviate this situation considerably, not only for this teaching team but for others in similar remote schools. ${ }^{1}$

(1) This research is supported by the Australia Research Council Centre of Excellence for the Dynamics of Language (CE140100041) and the University of Sydney School of Education and Social Work. I thank the teachers and school in this study for the opportunities to be involved in their work; Denise Angelo, Ken Cruickshank, Samantha Disbray, Catherine Hudson, Mark Richards, Ailsa Purdon and Jane Simpson for discussing earlier drafts of this article with me; and the two anonymous reviewers and journal editors for their valuable feedback. Any errors are mine. 
Key words: Australian Curriculum, remote community schooling, English language teaching, team teaching, assistant teachers, Aboriginal and Torres Strait Islander students.

\section{Introduction}

From 2012 to 2016 the newly established Australian Curriculum Assessment and Reporting Authority (ACARA) successively published Foundation-Year 10 curriculum content and achievement standards for eight learning areas/subjects: English, Mathematics, Science, Health \& Physical Education, Humanities \& Social Sciences, The Arts, Technologies, and Languages. While curriculum existed in all states and territories prior to the establishment of ACARA, the rationale for introducing a national curriculum centred on improving the quality, equity and transparency of Australia's education system, setting consistent standards across the country, and harnessing collective expertise for this common goal (ACARA, 2012). Review of the Australian Curriculum is scheduled on a six-yearly cycle to ensure it still meets the needs of the diversity of students and provides clear guidance for teachers (ACARA, 2020; Australian Education Council, 2019).

One important inclusion in the Australian Curriculum has been overt consideration of English as an Additional Language/ Dialect (EAL/D). ACARA advises teachers that Aboriginal and Torres Strait Islander students are among those who need to learn English, learn the curriculum content through English, and learn about English (ACARA, 2014e). This article takes the current review as a timely opportunity to consider how the curriculum and its support materials serve teachers and assistant teachers of EAL/D students who are speakers of traditional and new Indigenous languages in remote locations.

Previous research for schooling in these locations has centered on two main themes: remote communities' commitment to bilingual education, and the manifold problems associated with ACARA's National Assessment Plan - Literacy and Numeracy (NAPLAN) for Indigenous learners of unassessed English proficiency levels ${ }^{2}$ using materials of doubtful socio-cultural fairness. This article reviews that research and then draws attention to a major constituent in education provision which such research has largely bypassed, the curriculum. It examines the substantial - though largely unrecognised - language teaching required to make curriculum content accessible for L1 Indigenous 
language students, in the curriculum environment led by ACARA since 2012.

The classroom that serves to illustrate this context offers a descriptive account of on-the-ground experiences of a remote school Year 1-2 teaching team which comprises a non-Indigenous teacher and a teaching assistant from the local community who speaks the students' L1. In light of what this classroom context reveals, this article analyses Australian Curriculum content and the suite of ACARA resources which are intended to guide the $\mathrm{EAL} / \mathrm{D}$ aspects of teaching the various learning areas/subjects. The findings suggest pressing need for different national curriculum settings to better support educators in this context.

\section{Context and previous research}

This study is informed by the case of a Central Australian community school where students speak a traditional Aboriginal language from birth and subsequently add English through their schooling. English is best labelled as a foreign language in this community. That is, non-Indigenous native English speakers are a minority group, unlikely to be long-term residents. Local community members do use English, however it is not their preferred language of communication. Interpreting and translating services and support - official or informal - are required for many to effectively access government and non-government services.

This context is broadly characteristic of remote communities in parts of the NT, SA, Qld and WA where children speak traditional or new Indigenous languages as their L1. New Indigenous languages such as Kriol, Cape York Creole and Yumplatok (Torres Strait Creole), are contact languages distinctly different from any historical source language like English, and from present day Aboriginal Englishes, and have the highest number of speakers of all Indigenous languages in Australia (Angelo et al., 2019).

Previous research has established that families and educators in remote schools, have consistently advocated for both sides of 'a good education', i.e. schooling that values and incorporates the

\footnotetext{
(2) NAPLAN data is disaggregated for 'Indigenous' status and 'Language Background Other Than English (LBOTE)'. LBOTE provides only a broad indicator of language and cultural diversity, as it is defined on the basis of whether the student or either parent/caregiver speaks a language other than English. It does not indicate students' English proficiency. (Dixon \& Angelo, 2014).
} 
sophisticated knowledge systems embedded in the children's home language and culture and affirms their unique identity, alongside schooling that gives them access to the social capital enabled through English language competence and familiarity with non-Indigenous knowledge systems (e.g. Guenther, Osborne, Disbray, \& Bat, 2016; Marika, 2000; Purdon, 2010; Purdon \& Palmer, 2017). In the community where this study takes place, these aspirations were given expression through a bilingual program, which operated most strongly in the 1980s-1990s. The program generated and/or benefited from many concurrent initiatives, e.g. collaborations involving schools, linguists, vocational and higher education providers, L1 literacy skills development for adults, remote area teacher education programs, and local production of literature to support children's learning of their first language and culture. These initiatives all underpinned meaningful engagement of community members in their children's education (Devlin, Disbray, \& Devlin, 2017; Kral, 2017). Similar dual language programs were developed for other traditional languages spoken by children as their L1 in some communities in the NT, SA, Qld and WA. Also, although fewer in number, dual language programs operated in new Indigenous languages in the NT and Qld (Siegel, 1999) and played just as pivotal role in curriculum learning for their L1 speakers.

However over the past two decades, such linguistically responsive programs have been on the wane nationally, most thoroughly documented in the NT. A first round of cuts occurred in 1998, but the most severe and sudden reduction in bilingual education in remote NT communities coincided with the announcement of 'poor' results in ACARA's high stakes, highly publicised NAPLAN in 2008 (Devlin, 2011; Dickson, 2010; Hoogenraad, 2001; Nicholls, 2005; Simpson, Caffery, \& McConvell, 2009; Wilkins, 2008). Although NAPLAN performance was a general issue (not by any means limited to NT bilingual schools), ill-founded perceptions caused a policy shift in the NT which instituted four hours of English per day and relegated the use of Aboriginal languages to the time slot after lunch. This was based on the pedagogically misguided belief that teachers delivering more English-only lessons would improve students' acquisition of literacy and numeracy, yielding higher NAPLAN scores (Freeman, 2013; Macqueen et al., 2019; McIntosh, O'Hanlon, \& Angelo, 2012; Wigglesworth, Simpson, \& Loakes, 2011).

In response to protests from communities, educators and 
their supporters, there was a softening of the four hours English policy and notional encouragement to use students' L1 in classrooms. However, the number of officially resourced NT bilingual schools dropped from a height of 25 (between 1973 and 2008) to five (Disbray, 2014; Disbray \& Wigglesworth, 2019, pp. 368-369). Other schools with L1 Indigenous language speaking students now offer a discrete language-as-subject program rather than systematically integrated bilingual learning across the curriculum (Disbray, 2015). This is true for NT schools with traditional and new Indigenous language speaking students, and the same trend is also apparent in SA, Qld and WA. Provision of remote area teacher education suited to bilingual Aboriginal people was also severely reduced (Reaburn, Bat, \& Kilgariff, 2015). The only specific and long-term response for this context, bilingual education, has thus been whittled down.

It was in the midst of these socio-political realities for remote community schools that ACARA began leading development of new national curriculum for eight learning areas/subjects. Remote schools, whether officially dual language or predominantly English medium, have continued to acknowledge the need to support student learning across the curriculum by employing local community members who share the students' linguistic repertoire (Guenther \& Disbray, 2015). Classrooms are ideally though not always - staffed with a local bilingual assistant teacher who works alongside a registered teacher, often non-Indigenous. An extra hurdle for students and their communities who speak a new Indigenous language is the extent to which it is recognised as a distinct language. This is important because impetus for employing staff with the same language varieties as students hinges on awareness and status of new languages (Angelo, Fraser, \& Yeatman, 2019).

Teachers in remote schools may have a general awareness of the fundamental importance of language for successful teaching of Australian Curriculum content. For example, in EdmondsWathen's (2015) study of Primary years Mathematics, teachers report tensions between the standard curriculum, exhortations that they should have high expectations of their students, and the English language learning status of their students. However, teachers in such contexts struggle to cater for their students' learning needs, in the absence of language-informed curriculum, and under aggravated washback from ill-suited policy, such as use of NAPLAN scores for high stakes purposes. Commonly, they 
reach for commercial products not developed for English language learners, such as literacy packages that fail to teach English language skills more broadly, and that do not connect to curriculum content (Angelo, 2013; Fogarty, Riddle, Lovell, \& Wilson, 2017; Freeman, 2013).

Similarly, teachers instruct students in NAPLAN-favoured genres (e.g. persuasive text), discourse organisation (introductionarguments-conclusion) and formulaic phrases (in my opinion ..., everyone knows that ...) but do not have TESOL skills nor curriculum guidance for teaching English language elements at sentence and paragraph level (Angelo, 2012, 2013). Yet, such skills and guidance are essential for developing students' receptive and productive L2 English skills, and for enhancing student learning in curriculum delivered through English medium.

\section{Research aims and methods}

In remote schools where students' L1 is a traditional or a new Indigenous language, all teaching of curriculum content is, by default, also language teaching. Few studies have addressed the day-to-day work of teachers and teaching teams in this context, especially since the introduction of ACARA's Australian Curriculum.

This study has the following research questions:

1. To what extent are the current Australian Curriculum settings and guidance for teachers of EAL/D students matched to remote school contexts?

2. What teaching strategies work for the teaching team in this study?

3. What curriculum settings would better support teaching teams such as the one in this study?

This study takes a qualitative case approach, and draws on the notion of 'nesting' in Duff (2014), i.e. a richly described phenomenon (classroom teaching of L1 Indigenous language speaking students) in a larger social unit (remote schools in communities where English is a foreign language) in a wider socioeducational context (Australian Curriculum content and guidance for teachers of EAL/D students). In Stake's (2005) case study typology, this one can be categorised as instrumental, i.e. it aims to provide insight into an issue, to illuminate a phenomenon common to other similar cases.

The teaching team in this study works in a school of 150 
students, staffed with non-EAL/D-trained teachers, with access to one EAL/D advisor who visits the school once per term and whose energies are stretched across several other schools. The teaching team is a collaboration between a teacher with a Bachelor of Education who has worked in the school for 5 years, and an assistant teacher with a 3-year Diploma of Teaching who is a local community member and has 30 years experience in the school. The assistant teacher completed her Diploma in the 1980s when a remote area teacher education program and L1 literacy courses for adults were operating. This is a talented team, notable for the extent of their experience and strength of their partnership. The school's historical involvement in the bilingual education movement in Central Australia also underlies this team's capacity, and is a strength that not all remote schools in the NT, SA, Qld and WA are able to draw on.

I came to know the teaching team during my bi-annual month-long visits to the community, spread over 5 years, for my PhD work with families on maintenance of their endangered L1. I have been able to spend many weeks in their classroom, join lesson planning sessions, and gain direct insights into their work. In addition to these participant-observations, this study is informed by an interview with the teaching team in which I asked them about their classroom practices. I also became familiar with the curriculum documents and guides they must work with, in my attempts to work collegially with them and understand the challenges they face. A review of these documents and guides is fundamental to understanding the curriculum context the teaching team works within, and to addressing the first of the three research questions.

\section{Findings and analysis}

To what extent are the current Australian Curriculum settings and guidance for teachers of $E A L / D$ students matched to remote school contexts?

The standard Australian Curriculum for English, Mathematics, Science, Health \& Physical Education, Humanities \& Social Sciences, The Arts and Technologies applies to all Australian students. There is no dedicated curriculum pathway that recognises remote school students' English language learner status, and the languages they bring to school (Freeman \& Staley, 2018). The curriculum makes no time allowance for the extra English 
language teaching that should be provided so that they can access all of the content and knowledge in all learning areas/subjects. Further, the achievement standards for each year of learning in each learning area/subject are the same for all Australian students, regardless of their levels of English proficiency. Student progress in all learning areas/subjects is monitored through teacherdesigned assessment tasks, for the purposes of school-based records and reporting to parents.

In remote community school contexts, responsibility for ensuring students achieve the same standards as English-speaking students elsewhere in Australia principally lies with non-EAL/D-specialist teaching teams. To guide their planning and teaching, they can refer to the following three curriculum supports: EAL/D annotations, illustrations of practice and classroom resources.

\section{EAL/D annotations}

Guides intended to support non-specialist teachers to differentiate standard curriculum content for EAL/D students are available for only four of the eight learning areas/subjects: English, Maths, History and Science (ACARA 2014a, 2014b, 2014c, 2014d; 2014e). The guides 'annotate' content descriptions in each of the four learning areas/subjects with advice on language/cultural considerations and teaching strategies, as in Figure 1. These excerpts from the guide for Year 2 History are representative of the guidance the teaching team in this study works with.

This advice is on just a couple of language points (tense, comparison), and is exceedingly general. The minimal detail in the language/cultural considerations column contrasts with the extensive amount of English language needed to cover the curriculum content identified in the column on the left, which requires several lesson sequences in a teacher-planned program. For teachers who do not already have EAL/D qualifications and experience, the strategies suggested in the column on the right lack sufficient coverage of the requisite English language for this curriculum content. At best, the guidance serves as a flag to teachers that there is a need to differentiate their teaching for EAL/D learners.

Figure 1. Example advice to teachers in the EAL/D guide for Year 2 
History (ACARA, 2014b, pp. 6-9)

\begin{tabular}{|c|c|c|}
\hline CONTENT DESCRIPTIONS & $\begin{array}{l}\text { LANGUAGEICULTURAL } \\
\text { CONSIDERATIONS }\end{array}$ & TEACHING STRATEGIES \\
\hline $\begin{array}{l}\text { Historical skills } \\
\text { Distinguish between the past, } \\
\text { present and future } \\
\text { (ACHHSO4B) }\end{array}$ & $\begin{array}{l}\text { Subject-specific vocabulary is } \\
\text { challenging because EAL/D students will } \\
\text { have had limited exposure to these } \\
\text { words. } \\
\text { Distinguishing between the past, present } \\
\text { and future requires knowledge of the } \\
\text { tenses in English. English has a } \\
\text { complicated tense system, with several } \\
\text { ways of talking about the past, present } \\
\text { and future that are not interchangeable } \\
\text { and are used to make fine distinctions of } \\
\text { meaning. }\end{array}$ & $\begin{array}{l}\text { Teach subject-specific } \\
\text { vocabularyexplicitly and in } \\
\text { context (for example, war } \\
\text { memoria). } \\
\text { Use illustrated glossaries and } \\
\text { word walls so that vocabulary } \\
\text { canbe revisited throughout the } \\
\text { schoolday. } \\
\text { When looking at texts notice } \\
\text { the use of tenses and teach } \\
\text { these incontext. } \\
\text { Identify where EAL/D students } \\
\text { are on the language learning } \\
\text { progression continuum in order } \\
\text { to target tense teaching at a } \\
\text { level commensurate with the } \\
\text { learner's development. }\end{array}$ \\
\hline $\begin{array}{l}\text { Historical skills } \\
\text { Identify and compare features of } \\
\text { cbjects from the past and present } \\
\text { (ACHHSO51) }\end{array}$ & $\begin{array}{l}\text { The language of comparison in English } \\
\text { includes the use of the comparative } \\
\text { adjective forms. These include: adding '- } \\
\text { er' to one- or two-syllable adjectives - } \\
\text { This bookis funnier, using 'more' for } \\
\text { adjectives with three or more syllables - } \\
\text { This book is more beautiful, as well as } \\
\text { exceptions such as more fun not funner, } \\
\text { and the irregular comparativeadjectives } \\
\text { such as better, not gooder. }\end{array}$ & $\begin{array}{l}\text { For most native English } \\
\text { speakers, this is intultive } \\
\text { knowledge that comes from a } \\
\text { sense of what sounds right. } \\
\text { EAL/D students are more } \\
\text { efficiently taught this } \\
\text { knowledge. } \\
\text { When errors are nosiced, they } \\
\text { should be explained in the } \\
\text { context of how comparatives } \\
\text { are formed, rather than simply } \\
\text { corrected. }\end{array}$ \\
\hline
\end{tabular}

Some annotations specifically refer to Aboriginal and Torres Strait Islander EAL/D students. This advice appears as statements, some of which need revisiting for accuracy and applicability, scattered haphazardly throughout the four EAL/D guides. They do not predict or unpack details of the English language that will be required to teach the related curriculum content, e.g.:

- Many cultures have strong oral storytelling traditions (for example Aboriginal communities).

- Some languages/dialects (such as Aboriginal English) do not have an extensive use of referential pronouns.

- Ask parents or bilingual assistants to assist, as the students may know this vocabulary in their first language.

- EAL/D students, particularly Aboriginal and Torres Strait 
Islander students, may bring alternative perspectives to geological changes, the reasons behind extreme weather or the changes in the Earth's surface.

- Different cultures use different ways of classifying objects according to their needs. For example, an Aboriginal student may classify plants according to edible or inedible, rather than species.

\section{Illustrations of practice}

The Australian Curriculum website provides illustrations of practice, i.e. a small set of short videos (currently eight) to model planning and delivery of lessons in which teachers cater for diverse student needs in their classrooms. Each model lesson is linked to the relevant learning area/subject, year level and curriculum content code. The illustrations of practice grouped together in a section on 'diversity' combine gifted and talented students, students with a disability, and EAL/D students.

In these videos, the EAL/D students are a minority in the class; have English-speaking peers; live in urban settings; have a specialist EAL/D teacher working with them and in partnership with the classroom teacher; or else they are sufficiently advanced that the classroom teacher can use the literacy learning continuum used for L1 English-speaking students, and can work without the assistance of a specialist teacher. Such illustrations of practice strongly contrast with the remote schools context, where all students in all classes are EAL/D learners, and teachers have limited if any access to a specialist teacher.

\section{Classroom resources}

Content in all Australian Curriculum learning areas/subjects is hyperlinked to Education Services Australia's Scootle site, a repository of over 20,000 digital resources ${ }^{3}$. However, the audiovisual/written text of the resources assumes a viewing/reading audience with L1 (or advanced proficiency in) English. Unpacking the language and embedded cultural references, to make these resources comprehensible for $\mathrm{EAL} / \mathrm{D}$ learners, must happen at classroom level. Otherwise teachers, such as the teaching team in this study, must create their own resources which match their students' proficiency levels. A search for 'EAL/D' on the Scootle

\footnotetext{
${ }^{(3)}$ Supported by the Australian Government Department of Education.
} 
site currently generates only 11 results. None is for a curriculum area other than English; and none fits the school context in this study.

\section{What teaching strategies work for the teaching team in this study?}

Through the experiences of a remote school teaching team, this article now turns to illustrate on-the-ground consequences of the curriculum and curriculum support gaps identified above, and strategies implemented at the local level to attempt to fill those gaps. The teaching team in this study identified the following seven strategies as effective in their classroom for teaching various Australian Curriculum learning areas/subjects content.

1. Planning together. Although there is some time in the school timetable allocated to team planning and writing units of work, more is usually required to do it well. It is planning that enables the team to become familiar with the curriculum content and the English language in the selected teaching resources. The assistant teacher needs time to research ways to talk about key concepts in the students' L1.

2. Introducing key concepts. For a Geography unit on 'waste and recycling', the teacher found a commercially published non-fiction big-book on the topic. The content was age-appropriate and, although it featured waste and recycling in major cities, it could also be linked to comparable services and practices in the students' own community and in the nearest major town. The text, however, was extremely complex for the students' current stage of English language acquisition. As a first step the assistant teacher went through the book, discussing the images in detail with the students in their L1, to establish foundational concepts that would come up throughout the unit.

3. Intensive teaching of key words and phrases. In the 'waste and recycling' unit, key terms introduced to students were: reuse, biodegradable, waste, litter, reduce, environment, decompose, harm, recycle, landfill, conserve. During their planning time the teaching team first unpacked the meaning of each key term into plain English, which then enabled the assistant teacher to develop a translation. A class wall display included each key term together with a plain English explanation, an L1 translation, and a photo. The teaching team spent considerable time on this preparatory language engineering task, and required assistance from the school's L1 language and culture program teacher.

4. Localising the content. In a History unit on 'then and 
now' the teaching team chose the topics of housing, food, family roles, communication and transport. For each topic they presented sets of photos of much earlier through to more recent periods of time in the community. They sourced these from online audiovisual archives, and took their own photos around the community. The photo sets provided stimulus for the assistant teacher to talk about each topic in relation to community life from the early $20^{\text {th }}$ century, through to her own childhood, and life in the community today. Discussions were held in a mixture of the students' L1 and English, and involved concepts of past, present, same, different, long time ago, not so long ago, continuity and change. Amongst the activities in the unit, students sequenced images chronologically, and wrote captions for them.

5. Practical activities and concrete materials to build shared understandings. This strategy is a hallmark of Early Years and Primary Education, familiar to trained teachers. It is also supportive of learning curriculum content through English as L2 (Murray, 2010). For a Science unit the teaching team used toys and other objects in a series of hands-on experiments to teach concepts of gravity, force, pressure, push, pull, float, sink, air, resistance. For each experiment a lot of classroom talk in both languages preceded students recording their observations and findings, in drawings and heavily scaffolded sentences.

6. Story recordings. The teaching team made their own audio recordings of two stories popular for teaching English curriculum content with this age-group: Who sank the boat? (Allen, 1991) and My mob going to the beach (Emmerton, 2004). Each page was recorded in the students' L1 and English, followed by a chime to prompt a page turn. The teaching team worked with the school's L1 language and culture teacher to create the translations and recordings. The audio files could be used in whole-class guided reading, or by individual students for independent practice.

7. Small rotating groups. As a general practice, input from the teaching team is followed by group work. During this time, students complete some activities independently and also have small-group time with the assistant teacher and teacher. These are opportunities for the content taught to the whole class to be reinforced through students' L1 and scaffolded for their English proficiency levels.

These seven examples illustrate ways the teaching team strives to provide a rich learning environment across the curriculum, in ways that are inclusive of their students' L1 and L2. 
They developed their strategies intuitively, through what they described as a process of 'trial and error' or 'guess and feel', rather than with the support of pre-service training, pre-existing model lessons, or a curriculum pathway suited to their students.

Despite all of the factors that mark this teaching team as outstanding (outlined in the methods section above), they report that they cannot cover all curriculum content, due to the time their students require to learn both the language and content in the different learning areas/subjects. Yet for school-based records and bi-annual reporting to parents, the teaching team must measure their students' achievement of the same amount of content taught to L1 English students, and assign an A-E grade for each learning area/subject. The curriculum achievement standards do not recognise or reward students for the English language learning they have achieved, nor enable them to attain high grades. All of this is demoralising for the teaching team, the students and their parents/carers.

When teaching curriculum content through the students' L1, issues of translating arise. While some curriculum content may be straightforward for the assistant teacher to discuss with students in their L1, some requires significant language engineering. That is, there are no directly equivalent terms for the many culturally specific concepts that are inherent in the learning areas/subjects. So ways for discussing them in the students' L1 need to be created, as in strategies 3,5 and 6 above. In the interview, the assistant teacher also identified 'fraction' as difficult to translate. At first, she drew on her own bilingualism, and simply tried to think of ways to talk about it in her L1. Next she discovered it did not appear in the bilingual dictionary for her language. She consulted other bilingual staff members, and discovered they too have struggled to translate fraction and related terms, each in their own classrooms.

This anecdote is representative of the kind of interpreting and translating challenge that largely goes unnoticed every day in schools like the one in this study. Further, without broader planning, there can be little consistency in translations from one occurrence, one class, one year or one assistant teacher to the next. The teaching team spends substantial time painstakingly translating key terms into plain English and then into the students' L1. The teacher guides (e.g. Figure 1) provide no advice on this significant aspect of their work.

When teaching curriculum content through the students' 
L2, issues of English-medium education arise. The creative and interactional communication skills of the teacher are critical to student learning. To teach key concepts directly through English, she immerses the students in shared experiences, hands-on activities, gesture and images in conjunction with her speech. Such strategies are most useful for teaching vocabulary items and listening/comprehension skills, but are limited for teaching productive skills or longer constructions in spoken or written English. Without curriculum guidance, non-specialist teachers cannot be expected to have skills for analysing English, such as the 'complicated tense system' cursorily mentioned in Figure 1, nor for teaching those linguistic structures in the context of subjectspecific sentence and discourse patterns in all receptive and productive modes.

\section{What curriculum settings would better support teaching teams such as the one in this study?}

This case study has shown ways in which the Australian Curriculum does not reflect the language aspects of teaching in remote Indigenous community schools. Currently a stand-alone languageas-subject curriculum is available to support revitalisation and maintenance of traditional languages (ACARA, 2015). For all other learning areas/subjects the curriculum content and standards assume educators' capability for making the curriculum accessible to English language learners in remote schools.

Several inquiries over many years have called for TESOL skills development in pre-service teacher training and in-service professional learning for remote school staff (e.g. Disbray, Guenther, \& Osborne, 2015; Lee, Fasoli, Ford, Stephenson, \& McInerney, 2014; Silburn, Nutton, McKenzie, \& Landrigan, 2011; Wilson, 2015). One response is the Capability Framework for teaching Aboriginal and Torres Strait Islander EAL/D students, developed jointly by Indigenous educators and senior education department staff in NSW, NT, WA and Qld (Queensland Department of Education Training and Employment, 2013). It categorises knowledge and skills that teachers need, e.g. understanding the structure of English, teaching subject-specific English, and incorporating students' L1s, traditional or new. It is mapped to the Australian Professional Standards for Teachers (APST), not to teaching Australian Curriculum content.

Another recent response to developing teacher capability is 
the Teaching Aboriginal and Torres Strait Islander EAL/D students hub, which provides a set of online modules (https:// master.ealdhub.edu.au). This entry level professional learning resource (graduate level, in APST terms) assists teachers to begin to develop the kinds of capacities listed in the Capability Framework (above), e.g. understanding the potential range of language backgrounds of Indigenous students, assessing students' EAL/D proficiency levels and supporting their growth in the macroskills in English. Teacher participation in the modules is self-paced and self-directed, not interactive or moderated. The modules are not mapped to teaching Australian Curriculum content.

Both of these initiatives are helpful contributions but still leave generalist trained teachers in remote schools with no explicit guidance about teaching specific content in the Australian Curriculum learning areas/subjects. There is much potential for ACARA to contribute curriculum leadership to this endeavour of building teacher capability, given the powerful role of curriculum in driving day-in day-out classroom work.

ACARA could helpfully develop curriculum innovations that better recognise and direct the inherent and extensive language teaching and learning evident in the remote schools context in this article. An EAL/D curriculum for the English learning area/subject in the Primary years of schooling would recognise the one learning area/subject most fundamental to developing students' communication skills in a language which they encounter predominantly only at school. There is an ACARAled precedent for a purpose-built curriculum for a different group of EAL/D learners, i.e. the Senior Secondary EAL/D English curriculum, which was developed for students who are new to Australia and have had limited exposure to English. A dedicated curriculum pathway for Mathematics, Science, Health \& Physical Education, Humanities \& Social Sciences, The Arts and Technologies for remote school English language learners could better delineate the content to be covered, more explicitly identify the language needed to teach that content, and better signify a content and language integrated learning type of approach. Such innovations should not be read as suggesting lower expectations, but rather as responding to all the English language learning that underpins accessing the entire curriculum for students whose L1 is a traditional or new Indigenous language.

Students deserve learning that is purposefully promoted 
through the L1 they already know and through the L2 they need to be intentionally taught. Ideally, any ACARA-led curriculum innovation would be resourced with models and planning tools, similar to the ones currently provided (i.e. the EAL/D guides, illustrations of practice and Scootle resources discussed above), but tailored to the context described in this article. Such support would include guidance on the kinds of issues that arose in this article, e.g. how to instrumentalise an Indigenous language for teaching the different learning areas/subjects; how to plan and teach English language specific to all of that curriculum content (not only discourse/text structure); what constitutes the correct order, stages and amount of English language to teach and alongside this, what is a reasonable and achievable amount of curriculum content given the English language learning context.

\section{Conclusion}

Through an analysis of current curriculum and guidance for teachers of EAL/D students, and the work of a teaching team, this case study has presented a descriptive account of challenges involved in teaching Australian Curriculum learning areas/ subjects in remote community schools where students' L1 is a traditional or new Indigenous language and their exposure to English is limited. It found that the task of making curriculum content accessible for these learners requires considerable language planning. Innovations to the current curriculum settings are required to better meet communities' desire for 'a good education' for their children. This requires targeted teaching of English language in the different curriculum areas and applying the students' L1 to curriculum learning; work for which schools without a history of bilingual education have less awareness of and capacity.

ACARA's own stated principles for the ongoing development of the Australian Curriculum are pertinent to the case study in this article, namely equitable access to education for all students, clear guidance for teachers, and harnessing expertise across jurisdictions (ACARA, 2012). ACARA has already established procedures for working collaboratively with Aboriginal and Torres Strait Islander educators. Their experience of using traditional or new Indigenous languages as a medium of instruction and supporting learners in English-medium classrooms, together with TESOL specialists, can provide important insights for curriculum renewal suited to remote community schools. Models 
of both Indigenous L1s and English as medium of instruction are means for achieving equitable education in remote community locations in the NT, SA, Qld and WA. The considerable resources that ACARA could draw together nationally would improve the match of curriculum to learner needs and strengths, and better guide and support teachers and teaching teams in this context.

\section{References}

Allen, P. (1991). Who sank the boat? Ringwood, Vic: Puffin.

Angelo, D. (2012). Sad stories. A preliminary study of NAPLAN practice texts analysing students' second language linguistic resources and the effects of these on their written narratives. In M. Ponsonnet, L. Dao, \& M. Bowler (Eds.), Proceedings of the 42nd Australian Linguistic Society Conference 2011 (pp. 27-57). Australian National University, Canberra, December 2-4.

Angelo, D. (2013). NAPLAN implementation: Implications for classroom learning and teaching, with recommendations for improvement. TESOL in Context, 23(1-2), 53-73.

Angelo, D., Fraser, H., \& Yeatman, B. (2019). The art of recognition. Visualising contact languages with community vernacular language posters. Babel, Journal of the Australian Federation of Modern Languages Teachers Associations, 54(1\&2), 34-40

Angelo, D., O’Shannessy, C., Simpson, J., Kral, I., Smith, H., \& Browne, E. (2019). Well-being and Indigenous language ecologies (WILE): A strengths-based approach. Literature Review. National Indigenous Languages Report, Pillar 2. Prepared for the Australian Government Department of Communications and the Arts. Canberra, ACT: Australian National University, Australia Research Council Centre of Excellence for the Dynamics of Language.

Australian Curriculum Assessment and Reporting Authority. (2012). The shape of the Australian Curriculum version 4. Sydney, NSW: ACARA.

Australian Curriculum Assessment and Reporting Authority. (2014a). English as an additional language or dialect teacher resource. Annotated content descriptions: English Foundation to Year 10. Sydney, NSW: ACARA. https://docs.acara.edu.au/ resources/EALD_Learning_Area_Annotations_English_ 
Revised_February_2014.pdf

Australian Curriculum Assessment and Reporting Authority. (2014b). English as an additional language or dialect teacher resource. Annotated content descriptions: History Foundation to Year 10. Sydney, NSW: ACARA.

Australian Curriculum Assessment and Reporting Authority. (2014c). English as an additional language or dialect teacher resource. Annotated content descriptions: Mathematics Foundation to Year 10. Sydney, NSW: ACARA.

Australian Curriculum Assessment and Reporting Authority. (2014d). English as an additional language or dialect teacher resource. Annotated content descriptions: Science Foundation to Year 10. Sydney, NSW: ACARA.

Australian Curriculum Assessment and Reporting Authority. (2014e). English as an additional language or dialect teacher resource. Overview and EAL/D learning progression Sydney, NSW: ACARA. https://docs.acara.edu.au/resources/ EALD_Overview_and_Advice_revised_February_2014.pdf

Australian Curriculum Assessment and Reporting Authority. (2015). F-10 Framework for Aboriginal languages and Torres Strait Islander Languages. Sydney, NSW: ACARA http:// www.australiancurriculum.edu.au/languages/frameworkfor-aboriginal-languages-and-torres-strait-islanderlanguages/.

Australian Curriculum Assessment and Reporting Authority. (2020). Terms of reference: Review of the Australian Curriculum F-10. Sydney, NSW: ACARA https://www.acara.edu.au/ curriculum/curriculum-review.

Australian Education Council. (2019). Alice Springs (Mparntwe) education declaration: Australian Education Council.

Devlin, B. (2011). The status and future of bilingual education for remote Indigenous students in the Northern Territory. Australian Review of Applied Linguistics, 34(3), 260-279.

Devlin, B., Disbray, S., \& Devlin, N. (2017). History of bilingual education in the Northern Territory: People, programs and policies. Singapore: Springer.

Dickson, G. (2010). No Warlpiri, no school? A preliminary look at attendance in Warlpiri schools since introducing the first four hours of English policy. Ngoonjook(35), 97-113. 
Disbray, S. (2014). At benchmark? Evaluating the Northern Territory bilingual education program. In L. Gawne \& J. Vaughan (Eds.), Selected papers from the 44th Conference of the Australian Linguistic Society, 2013 (pp. 126-143). Melbourne, Vic: University of Melbourne.

Disbray, S. (2015). Spaces for learning: Policy and practice for Indigenous languages in a remote context. Language and Education, 30(4), 317-336.

Disbray, S., Guenther, J., \& Osborne, S. (2015). Red dirt teaching. Developing the right workforce for remote schools. Alice Springs, Darwin NT: The Northern Institute, Charles Darwin University.

Disbray, S., \& Wigglesworth, G. (2019). Indigenous children's language practices in Australia. In G. Hogan-Brun \& B. O'Rourke (Eds.), The Palgrave handbook of minority languages and communities. London, UK: Palgrave Macmillan.

Dixon, S., \& Angelo, D. (2014). Dodgy data, language invisibility and the implications for social inclusion: A critical analysis of Indigenous student language data in Queensland schools. Australian Review of Applied Linguistics, 37(3), 213-233.

Duff, P. A. (2014). Case study research on language learning and use. Annual Review of Applied Linguistics, 34, 233-255.

Edmonds-Wathen, C. (2015). Indigenous language speaking students learning mathematics in English: Expectations of and for teachers. Australian Journal of Indigenous Education, 44(1), 48-58.

Emmerton, S. (2004). My mob, going to the beach. Thuringowa, Qld: Black Ink Press.

Fogarty, W., Riddle, S., Lovell, M., \& Wilson, B. (2017). Indigenous education and literacy policy in Australia: Bringing learning back to the debate. The Australian Journal of Indigenous Education, 1-13.

Freeman, L. (2013). NAPLAN: A Thin Veil of Fairness. Excerpt from Senate Submission into the effectiveness of NAPLAN. TESOL in Context, 23(1-2), 74-81.

Freeman, L., \& Staley, B. (2018). The positioning of Aboriginal students and their languages within Australia's education system: A human rights perspective. International journal of speech-language pathology, 20(1), 174. 
Guenther, J., \& Disbray, S. (2015). Why local staff matter in very remote schools. Paper presented at the Australian Association for Research in Education, Freemantle, WA. December 1, 2015.

Guenther, J., Osborne, S., Disbray, S., \& Bat, M. (2016). Red dirt education. A compilation of learnings from the Remote Education Systems project (e-book). Adelaide SA; Alice Springs, Darwin, NT: Ninti One and the Cooperative Research Centre for Remote Economic Participation.

Hoogenraad, R. (2001). Critical reflections on the history of bilingual education in Central Australia. In J. Simpson, D. Nash, M. Laughren, P. Austin, \& B. Alpher (Eds.), Forty years on: Ken Hale and Australian languages (pp. 123-150). Canberra, ACT: Pacific Linguistics.

Kral, I. (2017). Yipirinya school: That generation, this generation. In B. C. Devlin, S. Disbray, \& N. R. F. Devlin (Eds.), History of bilingual education in the Northern Territory: People, programs and policies (pp. 269-284). Singapore: Springer.

Lee, P., Fasoli, L., Ford, L., Stephenson, P., \& McInerney, D. (2014). Indigenous kids and schooling in the Northern Territory: An introductory overview and brief history of Aboriginal Education in the Northern Territory. Bachelor, NT: Batchelor Press.

Macqueen, S., Knoch, U., Wigglesworth, G., Nordlinger, R., Singer, R., McNamara, T., \& Brickle, R. (2019). The impact of national standardized literacy and numeracy testing on children and teaching staff in remote Australian Indigenous communities. Language Testing, 36(2), 265-287.

Marika, R. (2000). Milthun latju wäna romgu Yolngu. Valuing Yolngu knowledge in the education system. TESOL in Context, 10(2), 45-52.

McIntosh, S., O'Hanlon, R., \& Angelo, D. (2012). The (In)visbility of "language" within Australian educational documentation: Differentiating language from literacy and exploring particular ramifications for a group of "hidden" ESL/D Learners. In C. Gitsaki \& R. B. Baldauf (Eds.), Future directions in applied linguistics: local and global perspectives (pp. 447 - 468). Newcastle upon Tyne, UK: Cambridge Scholars.

Murray, F. (2010). English-additional-language students in the middle years of school: Students in a muddle? Literacy Learning: The Middle Years, 18(2), 1-12. 
Nicholls, C. (2005). Death by a thousand cuts: Indigenous language bilingual education programmes in the Northern Territory of Australia, 1972-1998. International Journal of Bilingual Education and Bilingualism, 8(2-3), 160-177.

Purdon, A. (2010). Living in the mainstream. Ngoonjook(35), 31-43.

Purdon, A., \& Palmer, I. (2017). We did it: A short history of bilingual/bicultural education at Ltyentye Apurte Catholic School. In B. C. Devlin, S. Disbray, \& N. R. F. Devlin (Eds.), History of bilingual education in the Northern Territory: people, programs and policies (pp. 293-306). Singapore: Springer.

Queensland Department of Education Training and Employment. (2013). Capability Framework. Teaching Aboriginal and Torres Strait Islander EAL/D learners. Brisbane, Qld: Senior Officers National Network of Indigenous Education (SONNIE), Departments of Education in NSW, NT, WA and Qld.

Reaburn, S., Bat, M., \& Kilgariff, C. (2015). Looking for a new common ground: a reflection on Batchelor Institute's teacher education training programs for remote Aboriginal education professionals in the Northern Territory (e-book). In H. Huijser, R. Ober, S. O'Sullivan, E. McRae-Williams, \& R. Elvin (Eds.), Finding the common ground: narratives, provocations and reflections from the 40 year celebration of Batchelor Institute (pp. 31-42). Batchelor, NT: Batchelor Press.

Siegel, J. (1999). Creoles and minority dialects in education: An overview.Journal of Multilingual and Multicultural Development, 20(6), 508-531.doi:10.1080/01434639908666387

Silburn, S. R., Nutton, G. D., McKenzie, J. W., \& Landrigan, M. (2011). Early years English language acquisition and instructional approaches for Aboriginal students with home languages other than English: a systematic review of the Australian and international literature. Darwin, NT: Report produced on behalf of the Northern Territory Department of Education and Training by the Centre for Child Development and Education, Menzies School of Health Research.

Simpson, J., Caffery, J., \& McConvell, P. (2009). Gaps in Australia's Indigenous language policy: dismantling bilingual education in the Northern Territory. Australian Institute of Aboriginal and Torres Strait Islander Studies discussion paper series. Discussion Paper 24. Canberra, ACT: AIATSIS. 
Stake, R. (2005). Qualitative case studies. In N. K. Denzin \& Y. S. Lincoln (Eds.), Handbook of qualitative research (3rd ed., pp. 443-466). London; New Delhi: Sage.

Wigglesworth, G., Simpson, J., \& Loakes, D. (2011). NAPLAN language assessments for Indigenous children in remote communities: Issues and problems. Australian Review of Applied Linguistics, 34(3), 320-343.

Wilkins, D. (2008). W(h)ither language culture and education in remote Indigenous communities of the Northern Territory? In Australian Review of Public Affairs. Sydney, NSW: The University of Sydney http://www.australianreview.net/ digest/2008/10/wilkins.html.

Wilson, B. (2015). A share in the future. Review of Indigenous Education in the Northern Territory. Darwin, NT: Department of Education.

Susan Poetsch teaches units of study on linguistics and language teaching in a Masters program for Indigenous Australian teachers of their own languages. Her $\mathrm{PhD}$ research is on children's language acquisition and use in home and school contexts in a remote Central Australian community. Her teaching career was in Primary education and TESOL.

susan.poetsch@sydney.edu.au 